and below this temperature implied by the word "about"; are they in the order of twenty-five, one hundred or more degrees? How is the time distinguished from the temperature factor; that is, how is the effect of long heating at a relatively low temperature differentiated from the effect of shorter heating at a higher temperature? Considerable variations are expected in primitive craftsmanship. We accept them as the indications of inexact methods. This fact, however, does not lessen our concern in the limits of quantitative accuracy of our analytical technique.

While the answers to these questions are doubtless obvious to the metallurgist, the general archaeologist, unfamiliar with the fundamentals of the investigation, must be eager for more information. The significance of the data afforded by the method would seem sufficient to insure its wide application in archaeological investigations.

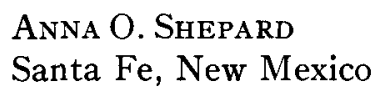

\title{
Survey Methods
}

While not wishing to detract from Mr. Robbins' laudable idea of an acceptable method for the designation of archaeological sites through the use of the U.S. Topographical Survey sheets, as presented in the January issue of this journal, it seems only fair to call his attention to the fact that such a system, with the detail sheet giving the essentials of the site listed, and available specimens, was inaugurated by Mr. Harold Gladwin of the Gila Pueblo, Globe, Arizona, early in 1928. In November, 1928, Mr. Gladwin, then residing in Pasadena, California, published a small brochure entitled, A Method for Designation of Ruins in The Southwest, which was "Privately Printed for The Medallion, Pasadena, California."

In this item is described the method mentioned by Mr. Robbins. In subsequent publications which have been issued from time to time by the members of the staff of the Gila Pueblo, this method has been used and seemingly has proved very satisfactory. The detail sheets upon which the archaeologists of the Gila Pueblo keep their field records are of a necessity more varied than those which Mr. Robbins might keep in New England.

It is interesting to note that two men who have come into the archaeological field after browsing in other pastures, men who have probably not contacted each other, and who live on opposite sides of the country, have hit upon the identical method for making archaeological surveys. We need more such interested students.

Arthur Woodward University of California Berkeley, California 